Tohoku J. Exp. Med., 2006, 208, 235-242

\title{
Cardiac Autonomic Hypofunction in Preschool Children with Short Nocturnal Sleep
}

\author{
Mari Sampei, Katsuyuki Murata, Miwako Dakeishi and Donald C. Wood ${ }^{1}$ \\ Departments of Environmental Health Sciences and ${ }^{1}$ Social Medicine, Akita \\ University School of Medicine, Akita, Japan
}

\begin{abstract}
Sampei, M., Murata, K., Dakeishi, M. and Wood, D.C. Cardiac Autonomic Hypofunction in Preschool Children with Short Nocturnal Sleep. Tohoku J. Exp. Med., 2006, 208 (3), 235-242 — Preschool children with sleep deficit may suffer from autonomic symptoms or hypotension. Heart rate variability, reflecting cardiac parasympathetic and sympathetic activities, and blood pressure were assessed to clarify the effects of nocturnal sleep duration on cardiac autonomic function in 134 preschool children aged 5 and 6 years. Parents reported their children's typical bedtimes and wake times for weekdays. In the children, the mean nocturnal sleep duration ( \pm standard deviation) was $575 \pm 42 \mathrm{~min}$. The parasympathetic and sympathetic activities and systolic blood pressure (SBP) were significantly lower in the 80 children with short sleep (nocturnal sleep duration $<10 \mathrm{hrs}$ ) than in the 54 children with long sleep ( $\geqq 10 \mathrm{hrs}$ ). Only the SBP was positively correlated with nocturnal sleep duration in the children $(p<0.001)$; also, short nocturnal sleep duration was significantly related to hypotension ( $\mathrm{SBP}<100 \mathrm{mmHg}$ ), as judged by multiple logistic regression analysis. Among the children, inverse correlations were seen between the parasympathetic activity and SBP and between the sympathetic activity and diastolic blood pressure $(p<0.05)$. These findings indicate that shortening of nocturnal sleep is associated with cardiac autonomic hypofunction and low SBP in preschool children. We suggest that sleep duration is an important predictor for autonomic development in childhood. - nocturnal sleep duration; cardiac parasympathetic and sympathetic activities; blood pressure; preschool children

(C) 2006 Tohoku University Medical Press
\end{abstract}

Little evidence has been established on the pathophysiology between sleep duration and adverse health effects in children, although various factors disturbing children's nocturnal sleep, for instance, socioeconomic status, televisionviewing and video game-playing habits, whether both parents work outside and whether one works shifts or not, exist in industrialized countries, and sleep habits and/or disorders are associated with mental impairment and motor handicap (Quine
1991; Piazza et al. 1996; Owens et al. 1999, 2000; Aronen et al. 2000). In addition, it has been speculated that onset of menarche may be linked with shortening of nocturnal sleep in school-aged girls (Murata and Araki 1993). Apart from sleep research in children, extremely long or short sleep in general population seems to be associated with several sleep and health problems (Kripke et al. 1979; Ohayon 2004). Since some adult diseases, such as coronary heart disease (CHD) and hyper-

Received December 21, 2005; revision accepted for publication December 30, 2005.

Correspondence: Katsuyuki Murata, M.D., Department of Environmental Health Sciences, Akita University

School of Medicine, 1-1-1 Hondo, Akita 010-8543, Japan.

e-mail: winestem@med.akita-u.ac.jp 
tension, have been reported to be connected with lifestyles in childhood (National High Blood Pressure Education Program Working Group 2004), it is crucial to investigate cardiac autonomic functions in reference to lifestyle-related sleep behaviors in children.

Short-term variations in heart rate are seen at all ages and are an important sign of normal homeostatic mechanisms of the cardiovascular system (Finley and Nugent 1995). Especially, heart rate variability (HRV) with frequencydomain analysis has emerged as a noninvasive method to assess cardiac autonomic activity quantitatively, and it seems to be highly reproducible under standardized conditions (Massin and von Bernuth 1997; Batten et al. 2000). Also, it has been suggested that subjects with low HRV had an adverse cardiovascular risk profile and an elevated risk of incident CHD and death (Dekker et al. 2000), and that cardiovascular autonomic function played an important role in increasing blood pressure levels associated with increased modulation of parasympathetic tone of the heart after puberty but not in preadolescents (Tanaka et al. 2000). In this way, HRV is thought to be a promising and reliable tool to provide a marker of less favorable health (Grandjean et al. 2004; Unalacak et al. 2004; Murata et al. 2006), and this approach should be applied to sleep research in children.

Preschool children with sleep deficit may suffer from autonomic symptoms or hypotension, because such children frequently complain about sleepiness and lassitude (Ishihara 2005). In spite of potential issues involved in the estimation of nocturnal sleep (Sekine et al. 2002), the duration between bedtime and wake time for weekdays in preschool children aged 5 to 6 years has been reported to be 10-11 hrs in Iceland (Thorleifsdottir et al. 2002), about $11 \mathrm{hrs}$ in Switzerland (Iglowstein et al. 2003), and 9.7-10.2 hrs in the U.S. (Crosby et al. 2005), while sleep durations in Hong Kong and Japan seem to be somewhat short (Ishihara 2005; Ng et al. 2005). Judging from these data, it could be hypothesized that the optimal duration of nocturnal sleep for preschool children is $10 \mathrm{hrs}$ or more. In this article, a cross- sectional study was carried out to clarify whether autonomic functions such as HRV parameters and blood pressure differed among Japanese preschool children with short sleep (i.e., nocturnal sleep duration $<10 \mathrm{hrs}$ ) and with long sleep ( $\geqq 10 \mathrm{hrs}$ ).

\section{Materials and Methods}

The nature of the procedures used in the present study was explained to parents at four nursery schools and two kindergartens in Akita, northern Japan, and their preschool children, who did not have past or present history of serious illness such as heart, kidney, neurological or metabolic disease, were invited to take part in our study. The study was carried out with the written consent of parents and approval of the ethical review committee at the Akita University School of Medicine, between June and July 2005. In total, 55 nursery school children and 79 kindergarteners were enrolled in this study. According to information from the preschool teachers and parents, there were no children suffering from any obvious disease including obstructive sleep apnea syndrome or upper airway resistance syndrome. Nursery schools in Akita have mandatory nap times of about 1.5 hrs (range, 1 to $1.8 \mathrm{hrs}$ ) in the afternoon, but kindergartens, in principle, have no nap times.

Using a questionnaire, parents reported their children's typical bedtimes and wake times for weekdays, the regularity of the times, birthdays, the number of children and their birth order, and parental occupations. After collecting the questionnaires, nocturnal sleep duration (min) was computed from the difference between bedtime and wake time for weekdays. Data on height and body weight for each child were obtained from their preschools, and the Kaup index, defined as $10 \times$ (body weight $[\mathrm{kg}]) /(\text { height }[\mathrm{cm}])^{2}$, was calculated as an obesity index.

The HRV was measured by a single trained examin$\mathrm{er}$, in a quiet room of the kindergarten or nursery school, using the Pocket-ECG WEC-7101 (Nihon Kohden Co., Tokyo) connected to an analog-to-digital converter (sampling time, $1 \mathrm{msec}$ ) and a computer. Also, blood pressure was measured twice by the same examiner with a mercury sphygmomanometer, 2 min after sitting in a chair with their backs supported and their arms bared and supported at heart level. The average of two measurements was used in the analysis. Systolic and diastolic blood pressures (SBP and DBP) were defined as the first and the fifth Korotkoff sounds. Considering breakfast and lunch times, these tests were conducted between 10:00 and 


\section{$11: 30$ on weekdays.}

After each child remained comfortably in the supine position for $10 \mathrm{~min}, 300 \mathrm{R}-\mathrm{R}$ intervals on electrocardiogram (ECG) were measured in real time and stored on a hard disc, and consecutive $100 \mathrm{R}-\mathrm{R}$ intervals with the minimal standard deviation (S.D.) were automatically extracted from the obtained data to reduce measurement error (Murata et al. 1992; Grandjean et al. 2004; Ishii et al. 2005). The $\mathrm{CV}_{\mathrm{RR}}(\%)$ was defined as the ratio of the S.D. of the R-R intervals to the average value $\left(R R_{\text {mean }}\right.$, $\mathrm{msec})$. The power spectrum of R-R intervals was computed by autoregressive spectral analysis according to the Akaike information criteria (Akaike 1974). The spectrum of each of two components, i.e., the high frequency (HF) component at the center frequency of $0.15-0.4 \mathrm{~Hz}$ and low frequency (LF) component at $0.01-0.15 \mathrm{~Hz}$, was separated by component analysis (Fig. 1). Each component coefficient of variation (i.e., $\mathrm{CCV}_{\mathrm{HF}}$ and $\mathrm{CCV}_{\mathrm{LF}}$ ) was defined as the ratio of the square root of each component power spectral density $\left(\mathrm{PSD}_{\mathrm{k}}, \mathrm{msec}^{2}\right)$ to the $\mathrm{RR}_{\text {mean }}$ : $\mathrm{CCV}_{\mathrm{k}}(\%)=100 \times\left(\mathrm{PSD}_{\mathrm{k}}\right)^{1 / 2} / \mathrm{RR}_{\text {mean }}$, where $\mathrm{k}=\mathrm{HF}$ or LF. Since parasympathetic blockade with atropine abolishes the HF component but $\beta$-sympathetic blockade has no effect, the $\mathrm{PSD}_{\mathrm{HF}}$ and $\mathrm{CCV}_{\mathrm{HF}}$ reflects the parasympathetic activity (Pagani et al. 1986; Task Force of the European Society of Cardiology and the North American Society of Pacing and Electrophysiology 1996). In addition, the LF component is considered to be derived from the fluc- tuation in the vasomotor activity through the baroreflex mechanism and to show a $\beta$-adrenergically mediated increase in the standing posture. Therefore, the PSD $_{\mathrm{LF}}$ and $\mathrm{CCV}_{\mathrm{LF}}$ are thought to reflect the sympathetic activities, and the $\mathrm{LF} / \mathrm{HF}$ ratio (i.e., $\mathrm{PSD}_{\mathrm{LF}} / \mathrm{PSD}_{\mathrm{HF}}$ ) represents a sympathovagal balance.

The differences between the nursery school children and kindergarteners and between boys and girls were determined by Student's $t$-test or the Fisher exact test. According to nocturnal sleep durations, preschool children were divided into two subgroups, i.e., 80 children with short sleep ( $<10 \mathrm{hrs}$ ) and 54 children with long sleep ( $\geqq 10 \mathrm{hrs}$ ). As the $\mathrm{PSD}_{\mathrm{LF}}$, $\mathrm{PSD}_{\mathrm{HF}}$, and $\mathrm{LF} / \mathrm{HF}$ ratio were highly skewed to the left, these were transformed into common logarithmic values in the following analyses. The significance levels of differences in HRV parameters, SBP and DBP between the children with short sleep and with long sleep were tested by analysis of covariance to control for possible confounders such as age, sex, Kaup index, and institute variable. The institute variable was scored as "nursery school" = 1 and "kindergarten" $=2$. The correlations between nocturnal sleep duration and autonomic functions among all children were examined by the Pearson's product moment correlation coefficient; when the correlation was significant $(p<0.05)$, multiple regression analysis was used to control for age, sex, Kaup index, and institute variable. Also, the correlations between HRV parameters and

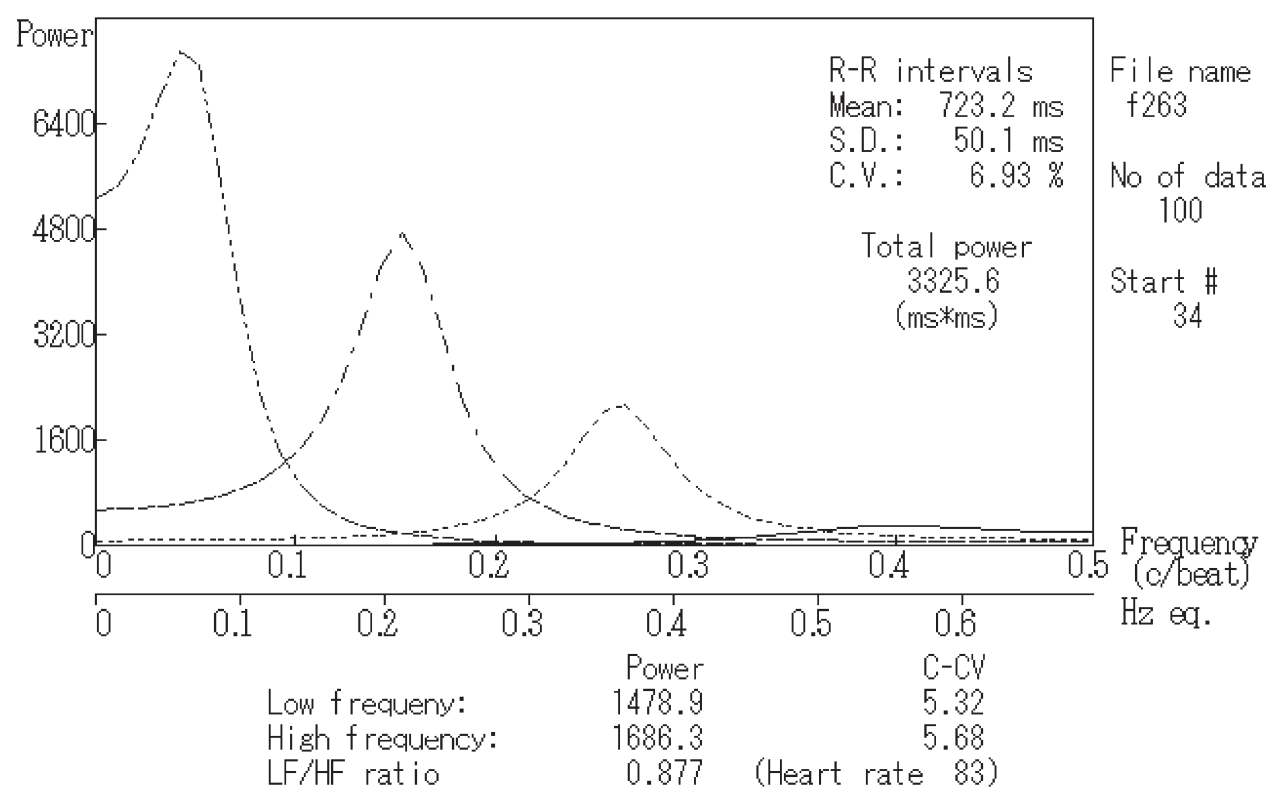

Fig. 1. An example of component analysis after autoregressive spectral analysis of ECG R-R intervals in a preschool child. 
blood pressure were tested by the partial correlation coefficient $(r)$ with the above confounders. All analyses, with two sided $p$ values, were performed with the Statistical Package for the Biosciences (Murata and Yano 2002).

\section{Results}

There were no children with either abnormal beats or ventricular extrasystoles on ECG, and no child took medication or caffeine-containing products on the morning of the examination. The mean nocturnal sleep duration ( \pm S.D.) was $575 \pm$ 42 (range, 480 to 690 ) $\mathrm{min}$ in the 134 preschool children. Table 1 presents the characteristics in 55 nursery school children and 79 kindergarteners. The nocturnal sleep duration was significantly shorter in the nursery school children than in the kindergarteners, although the former were significantly younger and smaller than the latter. Also, bedtimes in the nursery school children were significantly delayed as compared to those in the kindergarteners. There was no sex difference either in HRV parameters or blood pressure $(p>0.05)$.

The $\mathrm{CV}_{\mathrm{RR}}, \mathrm{CCV}_{\mathrm{LF}}, \mathrm{CCV}_{\mathrm{HF}}, \log \left[\mathrm{PSD}_{\mathrm{LF}}\right]$, $\log \left[\mathrm{PSD}_{\mathrm{HF}}\right]$, and $\mathrm{SBP}$ were significantly lower in

TABLE 1. Characteristics in 55 nursery school children and 79 kindergarteners in Japan (mean \pm S.D.)

\begin{tabular}{lccc}
\hline & Nursery school children & Kindergarteners & Probability \\
\hline Girls (number) & $21(38.2 \%)$ & $35(44.3 \%)$ & 0.594 \\
Age (months) & $64.7 \pm 7.0$ & $69.1 \pm 3.4$ & $<0.001$ \\
Height (cm) & $110.0 \pm 5.9$ & $112.7 \pm 4.4$ & 0.006 \\
Body weight (kg) & $18.7 \pm 2.5$ & $19.5 \pm 2.5$ & 0.081 \\
Kaup index & $15.4 \pm 1.2$ & $15.3 \pm 1.2$ & 0.574 \\
Only child (number) & $18(32.7 \%)$ & $11(13.9 \%)$ & 0.011 \\
Mother with job (number) & $53(96.4 \%)$ & $30(38.0 \%)$ & $<0.001$ \\
Nocturnal sleep duration (min) & $549 \pm 27$ & $593 \pm 41$ & $<0.001$ \\
Bedtime (hour) & $21: 41 \pm 29(\mathrm{~min})$ & $21: 08 \pm 42(\mathrm{~min})$ & $<0.001$ \\
Wake time (hour) & $06: 50 \pm 34(\mathrm{~min})$ & $07: 01 \pm 29(\mathrm{~min})$ & 0.040 \\
\hline
\end{tabular}

TABLE 2. HRV parameters and blood pressure (mean \pm S.D.) in 80 children with short sleep $(<10$ hrs) and 54 children with long sleep ( $\geqq 10 \mathrm{hrs}$ )

\begin{tabular}{|c|c|c|c|c|c|}
\hline & \multicolumn{2}{|c|}{ Preschool children } & \multirow{2}{*}{$\begin{array}{c}t \text {-test } \\
\text { Probability }\end{array}$} & \multicolumn{2}{|c|}{ Analysis of covariance with } \\
\hline & with short sleep & with long sleep & & $\begin{array}{c}3 \text { covariates }{ }^{\text {a }} \\
\text { probability }\end{array}$ & $\begin{array}{c}4 \text { covariates }^{\mathrm{b}} \\
\text { probability }\end{array}$ \\
\hline $\mathrm{CV}_{\mathrm{RR}}(\%)$ & $5.72 \pm 2.08$ & $6.61 \pm 2.45$ & 0.027 & 0.049 & 0.092 \\
\hline $\mathrm{CCV}_{\mathrm{LF}}(\%)$ & $3.85 \pm 1.75$ & $4.80 \pm 2.35$ & 0.013 & 0.010 & 0.029 \\
\hline $\mathrm{CCV}_{\mathrm{HF}}(\%)$ & $3.46 \pm 1.89$ & $4.41 \pm 2.23$ & 0.009 & 0.018 & 0.079 \\
\hline $\log \left(\mathrm{PSD}_{\mathrm{LF}}\left[\mathrm{msec}^{2}\right]\right)$ & $2.70 \pm 0.45$ & $2.91 \pm 0.41$ & 0.006 & 0.007 & 0.016 \\
\hline $\log \left(\mathrm{PSD}_{\mathrm{HF}}\left[\mathrm{msec}^{2}\right]\right)$ & $2.57 \pm 0.52$ & $2.81 \pm 0.51$ & 0.009 & 0.014 & 0.049 \\
\hline $\log (\mathrm{LF} / \mathrm{HF}$ ratio $)$ & $0.12 \pm 0.41$ & $0.10 \pm 0.41$ & 0.720 & 0.838 & 0.912 \\
\hline $\mathrm{SBP}(\mathrm{mmHg})$ & $96 \pm 10$ & $102 \pm 10$ & 0.001 & 0.009 & 0.095 \\
\hline $\mathrm{DBP}(\mathrm{mmHg})$ & $60 \pm 9$ & $63 \pm 9$ & 0.107 & 0.341 & 0.414 \\
\hline Heart rate $(/ \mathrm{min})$ & $94 \pm 9$ & $92 \pm 9$ & 0.226 & 0.404 & 0.230 \\
\hline
\end{tabular}

${ }^{a}$ Age, sex and Kaup index were controlled for.

${ }^{\mathrm{b}}$ Age, sex, Kaup index and institute variable were controlled for. 
the 80 children with short sleep than in the 54 children with long sleep (Table 2). The significance of these differences remained unchanged even after adjusting for age, sex, and Kaup index (Table 2). However, with an additional covariate (i.e., institute variable), only the $\mathrm{CCV}_{\mathrm{LF}}$, $\log \left[\mathrm{PSD}_{\mathrm{LF}}\right]$, and $\log \left[\mathrm{PSD}_{\mathrm{HF}}\right]$ differed significantly between the two subgroups. In the analysis of covariance of Table 2, age and Kaup index were related to blood pressure $(p<0.05)$ but the covariates were not related to any HRV parameters $(p>$ $0.05)$. Given the mean nocturnal sleep duration (i.e., $575 \mathrm{~min}$ ) instead of $10 \mathrm{hrs}$, the results were similar to those of Table 2 (data not shown).

Of the autonomic functions, only the SBP had a significant correlation with nocturnal sleep duration in the 134 preschool children $(r=0.287$, $p<0.001)$; while, the significant relation disappeared (standard regression coefficient $=0.180$, $p=0.061$ ) when using multiple regression analysis with independent variables of age, sex, Kaup index, and institute variable. Also, when preschool children were divided into two subgroups, i.e., 58 children with hypotension (i.e., SBP $<100$ $\mathrm{mmHg})$ and 76 children with normal SBP $(\geqq 100$ $\mathrm{mmHg}$ ), nocturnal sleep duration of explanatory variables in multiple logistic regression analysis was significantly related to hypotension $(p=$ 0.031 )

Concerning correlations between HRV parameters and blood pressure in the preschool children, the SBP had a close relation mainly to the $\mathrm{CCV}_{\mathrm{HF}}$ and $\log \left[\mathrm{PSD}_{\mathrm{HF}}\right]$; likewise, the DBP had a close relation to the $\mathrm{CCV}_{\mathrm{LF}}$ and $\log \left[\mathrm{PSD}_{\mathrm{LF}}\right]$ (Table 3).

\section{DisCUSSION}

In this study, the nursery school children showed short nocturnal sleep duration and delayed bedtime as compared to the kindergarteners, while almost all of their families belonged to the socioeconomic middle-upper class. The reason for delayed bedtime in the former would probably be that most mothers with nursery school children worked and often came home late for dinner. These findings are consistent with another report written by Japanese researchers (Fukuda and Sakashita 2002). They investigated whether daytime naps could compensate for sleep insufficiency on the previous night, and concluded that daytime naps in nursery schools appeared to cause delayed sleep onset but was not a result of sleep deficit. Also, the average nocturnal sleep duration in our 134 subjects was similar to those (566-609 $\mathrm{min}$ ) calculated from preschool children, aged 5-6 years, residing in other Japanese prefectures (Ishihara 2005), whereas it was remarkably short in Hong Kong primary school children at 6 years of age $(546 \pm 59 \mathrm{~min})(\mathrm{Ng}$ et al. 2005). Unfortunately, as preschool teachers did not always examine actual daytime nap duration for each child, we could not address the issue.

TABLE 3. Correlation coefficients between HRV parameters and systolic and diastolic blood pressure (SBP and DBP) among 134 preschool children, before and after controlling for age, sex, Kaup index, and institute variable

\begin{tabular}{|c|c|c|c|c|}
\hline & \multicolumn{2}{|c|}{ Simple correlation } & \multicolumn{2}{|c|}{ Partial correlation } \\
\hline & SBP & DBP & SBP & DBP \\
\hline $\mathrm{CV}_{\mathrm{RR}}$ & $-0.212^{*}$ & $-0.218^{*}$ & $-0.271^{* *}$ & $-0.256^{* *}$ \\
\hline $\mathrm{CCV}_{\mathrm{LF}}$ & -0.127 & $-0.174^{*}$ & -0.163 & $-0.182^{*}$ \\
\hline $\mathrm{CCV}_{\mathrm{HF}}$ & -0.148 & -0.133 & $-0.245^{*}$ & $-0.180^{*}$ \\
\hline $\log \left(\mathrm{PSD}_{\mathrm{LF}}\right)$ & -0.157 & $-0.183^{*}$ & $-0.198^{*}$ & $-0.197^{*}$ \\
\hline $\log \left(\mathrm{PSD}_{\mathrm{HF}}\right)$ & -0.168 & -0.136 & $-0.247^{* *}$ & -0.168 \\
\hline $\log (\mathrm{LF} / \mathrm{HF}$ ratio) & 0.045 & -0.023 & 0.099 & 0.001 \\
\hline Heart rate & $0.271^{* *}$ & 0.112 & $0.319^{* *}$ & 0.152 \\
\hline
\end{tabular}

${ }^{*} p<0.05,{ }^{* *} p<0.01$. 
We therefore considered only nocturnal sleep duration, and not total sleep duration, in relation to cardiac autonomic function, inasmuch as reported sleep duration could be used in a survey that requires data on relative differences in sleeping hours within a given population (Sekine et al. 2002).

The principal finding of our study was that all HRV parameters, excluding the LF/HF ratio, in the preschool children with short sleep were significantly decreased compared to those with long sleep. Also, the above associations, i.e., with the $\mathrm{CCV}_{\mathrm{LF}}, \log \left[\mathrm{PSD}_{\mathrm{LF}}\right]$, and $\log \left[\mathrm{PSD}_{\mathrm{HF}}\right]$, were statistically significant even after the institute variable was added into covariates of analysis of covariance. Probably, the institute variable would reflect the presence/absence of a daytime nap in each preschool rather than familial socioeconomic status, implying that daytime nap may not potently affect cardiac autonomic function at 5-6 years of age. Accordingly, the implication is that cardiac parasympathetic and sympathetic hypoactivities may be caused mainly by short nocturnal sleep in preschool children.

Similarly, SBP was significantly decreased in the children with short sleep as compared to those with long sleep (Table 2), and was significantly correlated with nocturnal sleep duration, whereas the significant association was not observed in using the institute variable, together with age, sex, and Kaup index, as covariates. In addition, short nocturnal sleep duration was associated with hypotension, which would not exactly imply that preschool children with such hypotension were ill because SBP/DBP (mean \pm S.D.) in Japanese children aged 5 years have been reported to be $101 \pm$ $10 / 53 \pm 8 \mathrm{mmHg}$ for 856 boys and $102 \pm 10 / 54 \pm$ $9 \mathrm{mmHg}$ for 801 girls (Hashimoto et al. 1997). Based on these findings, it is suggested that stationary SBP may reflect nocturnal sleep duration in preschool children. Also, daytime nap duration can potentially confound the SBP. Further research is necessary to elucidate the direct effect of daytime nap duration on blood pressure.

In the present study, both SBP and DBP were inversely connected with the $\mathrm{CV}_{\mathrm{RR}}, \mathrm{CCV}_{\mathrm{HF}}$, and $\log \left[\mathrm{PSD}_{\mathrm{LF}}\right]$. Tanaka et al. (2000) reported that 56 adolescents at ages 12-16 years had significant inverse correlations between $\mathrm{CCV}_{\mathrm{HF}}$ and both SBP and DBP, though 71 preadolescents at ages 6-11 years did not. Also, a significant inverse correlation between $\log \left[\mathrm{PSD}_{\mathrm{HF}}\right]$ and $\mathrm{DBP}$ was observed in day workers (Murata et al. 2005). That is, such inverse associations between HRV parameters and blood pressure exist in healthy children and adults, despite the fact that blood pressure depends on age (Hashimoto et al. 1997; National High Blood Pressure Education Program Working Group 2004). On the other hand, it has been suggested that reduced parasympathetic function and the sympathovagal imbalance such as high $\mathrm{LF} / \mathrm{HF}$ ratio are associated with the risk of developing hypertension (Petretta et al. 1995; Liao et al. 1996). Accordingly, the disruption or attenuation of associations between cardiac autonomic activities and blood pressure may be a key factor of essential hypertension; whereas, whether the link is causal remains unclear (Tanaka et al. 2000) and the implication in the cardiovascular system awaits further research. At least, we could not find a significant difference in the LF/HF ratio between the preschool children with short sleep and with long sleep.

The Task Force on HRV Standards points out that spectral analysis of 24-hrs recordings may not provide detailed information about autonomic modulation of the R-R interval due to the lack of stationarity, and recommends that controlled 5 -min recordings processed in the frequency domain be used to study pathophysiologic mechanisms (Task Force of the European Society of Cardiology and the North American Society of Pacing and Electrophysiology 1996). We measured 300 R-R intervals in the supine position (i.e., approximately for $3 \mathrm{~min}$ in preschool children or for 5 min in adults), and HRV parameters were calculated from consecutive R-R intervals with minimal deviation; i.e., the process of R-R interval data extraction for spectral analysis does not depend on observers (Murata et al. 1992, 2005; Grandjean et al. 2004; Ishii et al. 2005). Liao et al. (1997) also computed LF- and HF-PSDs of HRV from 2-min beat-to-beat heart rate data in the Atherosclerosis Risk in Communities (ARIC) 
study. On the other hand, it is also indicated that the power of heart-rate modulation in the frequency range considered to reflect sympathetic activity (i.e., $\mathrm{PSD}_{\mathrm{LF}}$ ) tends to be lower than that of the actual activity and may be misinterpreted as a deficiency of sympathetic outflow (Hilz and Dütsch 2006). In applying spectral analysis with fast Fourier transformation, the ARIC study used records of beat-to-beat data of $2.5 \mathrm{~min}$ to capture a few cycles of low-frequency heart rate fluctuation (Liao et al. 1997). We employed a samplingtime of $1 \mathrm{msec}$ and the autoregressive spectral model, and the model does not seem to have caused such problems (Murata et al. 1992, 2005, 2006; Grandjean et al. 2004; Ishii et al. 2005). Thus, it is suggested that our findings were not heavily influenced by such measurement errors. In any case, it may make little sense to compare the value of $\mathrm{PSD}_{\mathrm{LF}}$ or $\mathrm{CCV}_{\mathrm{LF}}$ between two studies conducted by different researchers.

In conclusion, our data indicate that shortening of nocturnal sleep is strongly associated with cardiac autonomic hypofunction and low SBP in preschool children. Such changes in the HRV parameters and SBP may lead to dysautonomia or hypotension in the near future, inasmuch as the sympathovagal balance does not seem to have been affected by nocturnal sleep duration. In addition, no HRV parameters in our preschool children aged 5-6 years were influenced by age or sex, while the $\mathrm{CCV}_{\mathrm{HF}}$ and $\mathrm{CCV}_{\mathrm{LF}}$ are considered to decrease with progressive age (Murata et al. 1992; Tanaka et al. 2000; Antelmi et al. 2004); it may imply that the decreasing HRV in childhood is controlled more strongly by nocturnal sleep duration than by age, because sleep duration reduces in childhood (Thorleifsdottir et al. 2002; Iglowstein et al. 2003; Crosby et al. 2005; Ishihara 2005; $\mathrm{Ng}$ et al. 2005). Thus, sleep duration is suggested to be an important predictor for autonomic development in childhood. Additional studies of children are required to clarify the effects of sleep duration on developmental organs including the cardiovascular system.

\section{Acknowledgments}

This study was supported partly by a grant-in- aid for scientific research from the Ministry of Education, Culture, Sports, Science and Technology, Japan.

\section{References}

Akaike, H. (1974) A new look at the statistical model identification. IEEE Trans. Automat. Contr., 19, 716-723.

Antelmi, I., De Paula, R.S., Shinzato, A.R., Peres, C.A., Mansur, A.J. \& Grupi, C.J. (2004) Influence of age, gender, body mass index, and functional capacity on heart rate variability in a cohort of subjects without heart disease. Am. J. Cardiol., 93, 381-385.

Aronen, E.T., Paavonen, E.J., Fjallberg, M., Soininen, M. \& Torronen, J. (2000) Sleep and psychiatric symptoms in school-age children. J. Am. Acad. Child Adolesc. Psychiatry, 39, 502-508.

Batten, L.A., Urbina, E.M. \& Berenson, G.S. (2000) Interobserver reproducibility of heart rate variability in children (The Bogalusa Heart Study). Am. J. Cardiol., 86, 12641266.

Crosby, B., LeBourgeois, M.K. \& Harsh, J. (2005) Racial differences in reported and nocturnal sleep in 2- to 8-yearold children. Pediatrics, 115, 225-232.

Dekker, J.M., Crow, R.S., Folsom, A.R., Hannan, P.J., Liao, D., Swenne, C.A. \& Schouten, E.G. (2000) Low heart rate variability in a 2-minute rhythm strip predicts risk of coronary heart disease and mortality from several causes: the ARIC study. Circulation, 102, 1239-1244.

Finley, J.P. \& Nugent, S.T. (1995) Heart rate variability in infants, children and young adults. J. Auton. Nerv. Syst., 51, 103-108.

Fukuda, K. \& Sakashita, Y. (2002) Sleeping pattern of kindergarteners and nursery school children: function of daytime nap. Percept. Mot. Skills, 94, 219-228.

Grandjean, P., Murata, K., Budtz-Jørgensen, E. \& Weihe, P. (2004) Cardiac autonomic activity in methylmercury neruotoxicity: 14-year follow-up of a Faroese birth cohort. J. Pediatr., 144, 169-176.

Hashimoto, N., Kawasaki, T., Kikuchi, T. \& Uchiyama, M. (1997) Criteria of normal blood pressure and hypertension in Japanese preschool children. J. Hum. Hypertens., 11, 351-354.

Hilz, M.J. \& Dütsch, M. (2006) Quantitative studies of autonomic function. Muscle Nerve, 33, 6-20.

Iglowstein, I., Jenni, O.G., Molinari, L. \& Largo, R.H. (2003) Sleep duration from infancy to adolescence: reference values and generational trends. Pediatrics, 111, 302-307.

Ishihara, K. (2005) Sleep habits of infant and the problem. Jpn. J. Child Nurs., 28, 1459-1463.

Ishii, N., Dakeishi, M., Sasaki, M., Iwata, T. \& Murata, K. (2005) Cardiac autonomic imbalance in female nurses with shift work. Auton. Neruosci., 122, 94-99.

Kripke, D.F., Simons, R.N., Garfinkel, L. \& Hammond, E.C. (1979) Short and long sleep and sleeping pills. Is increased mortality associated? Arch. Gen. Psychiatry, 36, 103-116.

Liao, D., Cai, J., Barnes, R.W., Tyroler, H.A., Rautaharju, P., Holme, I. \& Heiss, G. (1996) Association of cardiac autonomic function and the development of hypertension; the ARIC study. Am. J. Hypertens., 9, 1147-1156.

Liao, D., Cai, J., Rosamond, W.D., Barnes, R.W., Hutchinson, R.G., Whitsel, E.A., Rautaharju, P. \& Heiss, G. (1997) Cardiac autonomic function and incident coronary heart 
disease: a population-based case-cohort study. The ARIC study. Am. J. Epidemiol., 145, 696-706.

Massin, M. \& von Bernuth, G. (1997) Normal ranges of heart rate variability during infancy and children. Pediatr. Cardiol., 18, 297-302.

Murata, K., Landrigan, P.J. \& Araki, S. (1992) Effects of age, heart rate, gender, tobacco and alcohol ingestion on R-R interval variability in human ECG. J. Auton. Nerv. Syst., 37, 199-206.

Murata, K. \& Araki, S. (1993) Menarche and sleep among Japanese schoolgirls: an epidemiological approach to onset of menarche. Tohoku J. Exp. Med., 171, 21-27.

Murata, K. \& Yano, E. (2002) Medical Statistics for EvidenceBased Medicine with SPBS User's Guide. Tokyo, Nankodo Publisher.

Murata, K., Yano, E., Hashimoto, H., Karita, K. \& Dakeishi, M. (2005) Effects of shift work on QTc interval and blood pressure in relation to heart rate variability. Int. Arch. Occup. Environ. Health, 78, 287-292.

Murata, K., Sakamoto, M., Nakai, K., Dakeishi, M., Iwata, T., Liu, X.-J. \& Satoh, H. (2006) Subclinical effects of prenatal methylmercury exposure on cardiac autonomic function in Japanese children. Int. Arch. Occup. Environ. Health, (in press).

National High Blood Pressure Education Program Working Group on High Blood Pressure in Children and Adolescents. (2004) The fourth report on the diagnosis, evaluation, and treatment of high blood pressure in children and adolescents. Pediatrics, 114, 555-576.

Ng, D.K., Kwok, K., Cheung, J.M., Leung, S., Chow, P., Wong, W.H., Chan, C. \& Ho, J.C. (2005) Prevalence of sleep problems in Hong Kong primary school children: a community-based telephone survey. Chest, 128, 1315-1323.

Ohayon, M.M. (2004) Interactions between sleep normative data and sociocultural characteristics in the elderly. $J$. Psychosom. Res., 58, 479-486.

Owens, J., Maxim, R., McGuinn, M., Nobile, C., Msall, M. \& Alario, A. (1999) Television-viewing habits and sleep disturbance in school children. Pediatrics, 104, e27.

Owens, J.A., Spirito, A., McGuinn, M. \& Nobile, C. (2000) Sleep habits and sleep disturbance in elementary school- aged children. J. Dev. Behav. Pediatr., 21, 27-36.

Pagani, M., Lombardi, F., Guzzetti, S., Rimoldi, O., Furlan, R., Pizzinelli, P., Sandrone, G., Malfatto, G., Dell'Orto, S., Piccaluga, E., Turiel, M., Baselli, G., Cenitti, S. \& Malliani, A. (1986) Power spectral analysis of heart rate and arterial pressure variabilities as a marker of sympatho-vagal interaction in man and conscious dog. Circ. Res., 59, 178-193.

Petretta, M., Marciano, F., Bianchi, V., Migaux, M.L., Valva, G., De Luca, N., Salemme, L., Berardino, S. \& Bonaduce, D. (1995) Power spectral analysis of heart period variability in hypertensive patients with left ventricular hypertrophy. Am. J. Hypertens., 8, 1206-1213.

Piazza, C.C., Fisher, W.W. \& Kahng, S.W. (1996) Sleep patterns in children and young adults with mental retardation and severe behavior disorders. Dev. Med. Child Neurol., 38, 335-344.

Quine, L. (1991) Sleep problems in children with mental handicaps. J. Ment. Defic. Res., 35, 269-290.

Sekine, M., Chen, X., Hamanishi, S., Wang, H., Yamagami, T. \& Kagamimori, S. (2002) The validity of sleeping hours of healthy young children as reported by their parents. $J$. Epidemiol., 12, 237-242.

Tanaka, H., Borres, M., Thulesius, O., Tamai, H., Ericson, M.O. \& Lindblad, L.E. (2000) Blood pressure and cardiovascular autonomic function in healthy children and adolescents. J. Pediatr., 137, 63-67.

Task Force of the European Society of Cardiology and the North American Society of Pacing and Electrophysiology. (1996) Heart rate variability: standards of measurement, physiological interpretation, and clinical use. Circulation, 93, 1043-1065.

Thorleifsdottir, B., Björnsson, J.K., Benediktsdottir, B., Gislason, T. \& Kristbjarnarson, H. (2002) Sleep and sleep habits from childhood to young adulthood over a 10 -year period. J. Psychosom. Res., 53, 529-537.

Unalacak, M., Aydin, M., Ermis, B., Ozeren, A., Sogut, A., Demirel, F. \& Unluoglu, I. (2004) Assessment of cardiac autonomic regulation in children with monosymptomatic nocturnal enuresis by analysis of heart rate variability. Tohoku J. Exp. Med., 204, 63-69. 